\title{
ICARUS - SOFTWARE EDUCACIONAL DE APOIO AO ENSINO DE CONTABILIDADE
}

\author{
André Luiz Brun - Unioeste - andrebrun@ hotmail.com \\ Marinês Luiza Guerra Dotto - Unioeste - ml.dotto@ terra.com.br \\ Carlos José Maria Olguín - Unioeste - prof.olguin@gmail.com
}

Resumo. É visível a evolução das tecnologias e as influências causadas por esta na sociedade. Este fato é notado também no processo de ensino-aprendizagem, onde os alunos e professores passaram a dispor de ferramentas computacionais que possibilitam novas abordagens de ensino. A contabilidade está inserida neste mesmo contexto, onde a tecnologia da informação tornou o processo contábil rápido e confiável. Este trabalho apresenta a implementação e validação de um sistema de apoio ao ensino da contabilidade - Icarus. O software desenvolvido tem por objetivo inserir gradativamente o acadêmico de contabilidade neste bojo tecnológico. O sistema atingiu os objetivos, pois se mostrou uma ótima forma prática de ratificar os conceitos aprendidos pelos alunos em sala.

Palavras-chave: Tecnologia da Informação, Software Contábil, Processo EnsinoAprendizagem.

\begin{abstract}
It can be seen the evolution of technology and the influences caused by that society. This fact is also noticed in the teaching-learning, where students and teachers now have the computational tools that enable new learning approaches. The accounting is entered in the same context, where information technology has made the process fast and reliable accounting. This paper presents the implementation and validation of a system to support the teaching of accounting called Icarus. The developed software is designed to gradually introduce the accounting academic in the bulge of technology. The system has reached the goals, because it proved a great practice way to ratify the concepts learned by students in the classroom.
\end{abstract}

Keywords: Information technology, Accounting Software, Teaching-learning process.

\section{Introdução}

O processo de ensino molda-se conforme as mudanças que ocorrem na sociedade. Há alguns anos, os professores correspondiam à necessidade dos alunos apenas com aulas expositivas e teorias em sala, onde o mestre era porta voz do conhecimento e os alunos eram incumbidos de ouví-lo.

Atualmente, com o advento das tecnologias, o aluno tornou-se mais crítico e independente, visto que possui novas fontes de conhecimento à disposição. Esse processo fez com que alguns professores deixassem de lado a maneira tradicional de ensino e buscassem outras formas de cativar a atenção dos alunos e ensiná-los.

Segundo Moran (2004), os estudantes passaram a ter novas abordagens para atingir o aprendizado, como a aplicação de apresentação de projeção em sala (que ainda apresenta um caráter semelhante ao antigo, apenas mais dinâmico), a utilização de laboratórios de prática, ensino à distância e principalmente o advento da Internet, que fez com que a disseminação de conhecimento atingisse um novo patamar.

A utilização da computação como ferramenta de auxílio ao aprendizado caminha desde as escolas fundamentais até o ensino universitário, estendendo-se aos cursos de pós-graduação. Este mesmo processo é verificado nas instituições de ensino superior (IES) dentro de diversos cursos, incluindo os de Ciências Contábeis.

O processo realizado pela contabilidade também foi alvo da evolução da tecnologia da informação. A função do contador deixou de possuir um caráter moroso, 
repetitivo e cansativo, que envolvia muitos registros manuais em controles físicos das empresas contabilizadas. Com o advento computacional, esse processo perdeu seu caráter maçante e tornou-se muito mais rápido e eficiente, eliminando ainda a utilização de quantidade considerável de papel. Enquadrado neste novo contexto, o contador deixou de ser um mero registrador de eventos contábeis e passou também a desempenhar funções de caráter mais analítico. Crisóstomo et al. (2002) apresentaram softwares desenvolvidos com o intuito de oferecer aos acadêmicos de contabilidade novas abordagens de aprendizado. Nestes softwares, os alunos podem simular situações reais de mercado, aplicando o conhecimento teórico adquirido em sala e fixando-o ao trabalhar com metodologias mais dinâmicas e eficazes.

Confirmando este crescente interesse nas aplicações computacionais como ferramentas de apoio ao aprendizado contábil, Eyerkaufer, Fietz e Domingues (2006) desenvolveram uma pesquisa onde analisaram o interesse dos envolvidos no ensino da contabilidade em IES do estado de Santa Catarina. Este estudo mostrou que alunos e professores apontaram a tecnologia da informação como fator imprescindível ao processo de ensino-aprendizagem.

Atualmente o ensino da contabilidade básica utiliza-se de softwares comerciais completos, que oferecem uma gama considerável de aplicações e que não ostenta preocupações pedagógicas. Este fato ocorre porque são raros softwares desenvolvidos com intuito educacional para o ensino da contabilidade introdutória, de forma a propiciar melhor aprendizado, obrigando os alunos a enfrentarem softwares complexos que não oferecem um ambiente cognitivo interessante.

Os acadêmicos, ao se depararem pela primeira vez com um sistema contábil tradicional, sentem-se desorientados, tendo em vista a gama considerável de funcionalidades providas pelo software. Esse impacto negativo, bem como a complexidade do sistema, gera nos estudantes impressões que podem influenciar negativamente o aprendizado ou mesmo a percepção do discente perante sistemas de contabilidade.

Para tentar evitar que este contato inicial seja negativo e que o aprendizado do aluno diante das funcionalidades dos sistemas, bem como suas aplicações, seja o mais proveitoso possível, é interessante que ele tenha um aprendizado gradativo, iniciando com sistemas mais simples e posteriormente tendo contato com abordagens mais complexas e detalhadas.

Assim, neste trabalho desenvolvemos um sistema com características simples, atendendo conceitos ergonômicos e pedagógicos, que possibilitem ao acadêmico esse aprendizado gradativo e um contato com a informática aplicada à contabilidade, tornando assim a sua formação profissional mais rica e eficiente. O sistema visou dar acesso às informações contábeis através de menus de ajuda presentes nos formulários do software.

\section{Materiais e Métodos}

Visando alcançar os objetivos apresentados na seção anterior, foi desenvolvido um software de apoio ao ensino de contabilidade introdutória - Icarus, oferecendo aos estudantes um primeiro contato com tecnologias que encontrarão no mercado de trabalho. Porém, como o foco deste trabalho não foi recriar softwares contábeis existentes e sim propor uma abordagem simples de aprendizagem, o desenvolvimento foi restrito às demonstrações contábeis básicas.

Icarus, considerando a classificação de softwares educacionais proposta por Galvis-Panqueva (1992) pode ser considerado um software de exercícios e prática pois permite ao professor aplicar exercícios práticos a serem realizados pelos estudantes com auxilio do aplicativo. Porém, Icarus traz ainda uma característica dos sistemas tutores 
visto que toda vez que o usuário possuir alguma dúvida, ele pode executar a função de ajuda para obter uma explanação sobre o conteúdo foco de seu estudo.

O software foi desenvolvido na linguagem Delphi 6, utilizando como sistema gerenciador de banco de dados o Firebird 2.1, trabalhando em ambiente Windows.

As funcionalidades desenvolvidas focam o ensino de técnicas contábeis básicas, pois pretende atender alunos da primeira e segunda série da graduação. O software prove o cadastramento de empresas para registro, permite lançamentos diários de movimentações do patrimônio, suporta o cadastramento do plano de contas para cada uma das empresas cadastradas e, baseado nos lançamentos, a construção do balanço patrimonial, razonetes, balancete de verificação e o demonstrativo do resultado do exercício. Todos estes relatórios podem ser vistos em tela ou impressos.

A estrutura destes demonstrativos foi construída atendendo aos padrões exigidos pela legislação atual, especificamente as Leis 11.638 de 2007 e 11.941 de 2009 que alteraram a Lei 6.404 de 1976, assim como as normas e princípios de contabilidade.

Por se tratar de um software educacional, onde o objetivo é a aprendizagem do aluno, em todas as telas existe uma opção de ajuda, que permite que o usuário veja o que está fazendo. Esta ajuda, além de elucidar o funcionamento do software, agrega uma série de explicações sobre o conteúdo utilizado para tais ações, ou seja, busca instruir o acadêmico sobre os conceitos inerentes aquele método contábil.

A etapa de coleta de requisitos foi feita em conjunto com a professora responsável pelo ensino das técnicas computacionais no campo da contabilidade e também com usuários de programas comerciais. Como resultados, foram levantados os tópicos principais necessários ao aprendizado da contabilidade e os pontos mais interessantes na visão do usuário da contabilidade em um software.

O desenvolvimento segue o modelo espiral apresentado em Pressman (2006). O planejamento coube ao desenvolvedor e à professora titular da disciplina de informática focada na contabilidade. Após analisado o contexto, iniciou-se o desenvolvimento. A fase de implementação foi acompanhada pelas pessoas da contabilidade envolvidas no processo. Este acompanhamento permitiu grande eficiência na etapa de construção do software pois, além de saber exatamente quais eram os objetivos a serem atingidos, eventuais dúvidas ou erros puderam ser atendidos ou corrigidos no momento em que eram descobertos.

$\mathrm{Na}$ etapa de construção da interface foram estudados outros softwares visando aproveitar a transferência positiva com relação, principalmente, à escolha dos ícones. $\mathrm{O}$ objetivo foi propor símbolos que fossem familiares aos usuários.

Outro ponto analisado durante o desenvolvimento do software foi de que este deveria possuir algumas características de usabilidade propostas por Nielsen (1994). Em particular, se deu maior atenção à facilidade de uso, para auxiliar a interação com os usuários e buscar despertar o interesse destes no desenvolvimento das atividades práticas.

Para validar o sistema fez-se um teste real, com uma aplicação do sistema para os alunos do curso de Ciências Contábeis, utilizando exemplos fictícios, de forma que eles pudessem aplicar todas as funcionalidades. Este processo de avaliação foi realizado no campus de Cascavel, nos laboratórios onde os alunos de contabilidade têm suas aulas práticas. Durante a aplicação do software, estiveram presentes 15 alunos da segunda série do curso de Ciências Contábeis. O restante da turma optou por não participar da avaliação.

\section{Resultados e Discussões}

V. 9 № 2, dezembro, 2011 
Diante das dificuldades geralmente apresentadas pelos usuários de sistemas, buscou-se criar interfaces amigáveis e simples de interação onde mesmo os menos familiarizados com sistemas informatizados pudessem realizar os processos de forma coesa e satisfatória.

A tela principal do software agrega um menu de opções que os usuários podem escolher ao desenvolver seu trabalho. Estas funcionalidades permitem cadastros $\mathrm{e}$ construção de relatórios. Dentro dos cadastros, podem ser inseridas novas empresas, perante as quais os lançamentos e demonstrativos irão incidir. $\mathrm{O}$ acadêmico pode criar um plano de contas específico para cada empresa cadastrada conforme o ramo de atividade, como acontece no mercado de trabalho, onde este plano varia de entidade para entidade.

O sistema Icarus permite também a escrituração dos lançamentos contábeis ocorridos na empresa. E, no âmbito dos demonstrativos, o software é capaz de elaborar balanços patrimoniais, diários, razões, balancetes de verificação e também demonstrativos de resultados do exercício, baseados nos lançamentos feitos pelos alunos. Estes demonstrativos podem ser visualizados em tela ou impressos, visto que as duas abordagens são inerentes ao processo de escrituração e análise contábil.

A Figura 1 contém a tela de cadastro de empresas. Nas telas de interação todos os campos que possuem caráter obrigatório são marcados com um asterisco ao lado do nome para indicar esta condição. $\mathrm{O}$ acesso aos botões de ação em cada uma das telas é limitado de acordo com as funcionalidades pertinentes ao módulo em que o usuário está interagindo.

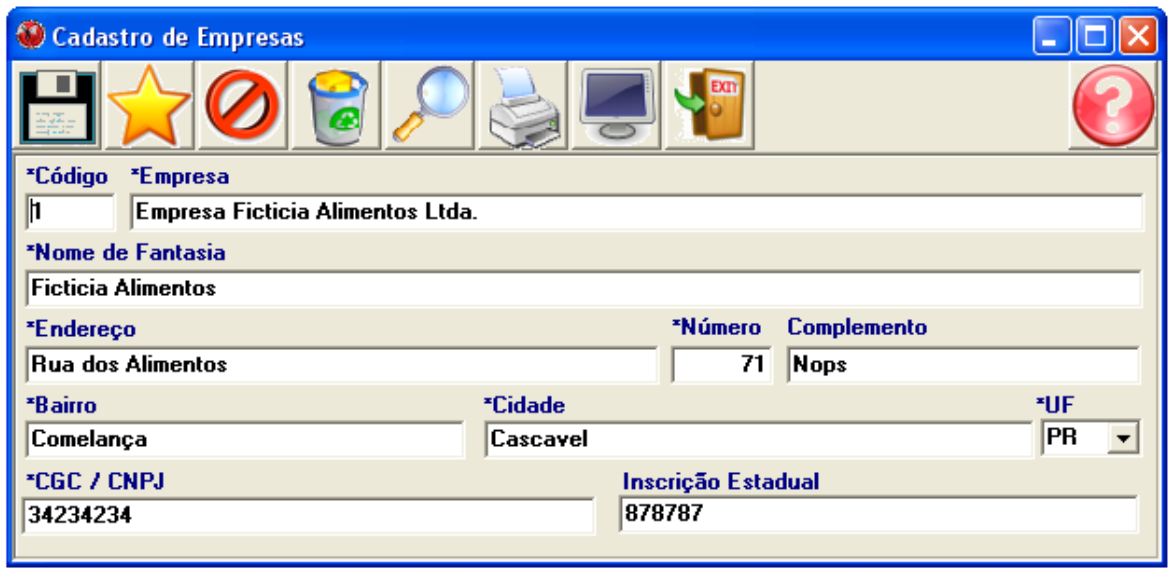

Figura 1 - Cadastro de empresas.

A Figura 2 exibe a tela onde o usuário pode consultar uma empresa já cadastrada. Esse processo de consulta pode ser feito com base no nome de fantasia, razão social ou endereço da empresa.

A Figura 3 apresenta a tela onde é realizado o cadastro do plano de contas para cada empresa. Como o plano varia de acordo com a empresa, o usuário pode cadastrar um plano de contas específico para cada uma seguindo os princípios e os procedimentos contábeis. Nota-se que o acadêmico deve especificar para qual empresa determinada conta está sendo cadastrada e também a natureza do grupo em questão. A imagem exibe o cadastro dos grupos de contas primárias, com uma característica bastante fixa, com a possibilidade de adaptar-se a mudanças na legislação ou normas contábeis. Neste cadastro são registrados os grupos de Ativo Circulante e Não Circulante, Passivo Circulante e Não Circulante, bem como Patrimônio Líquido. 


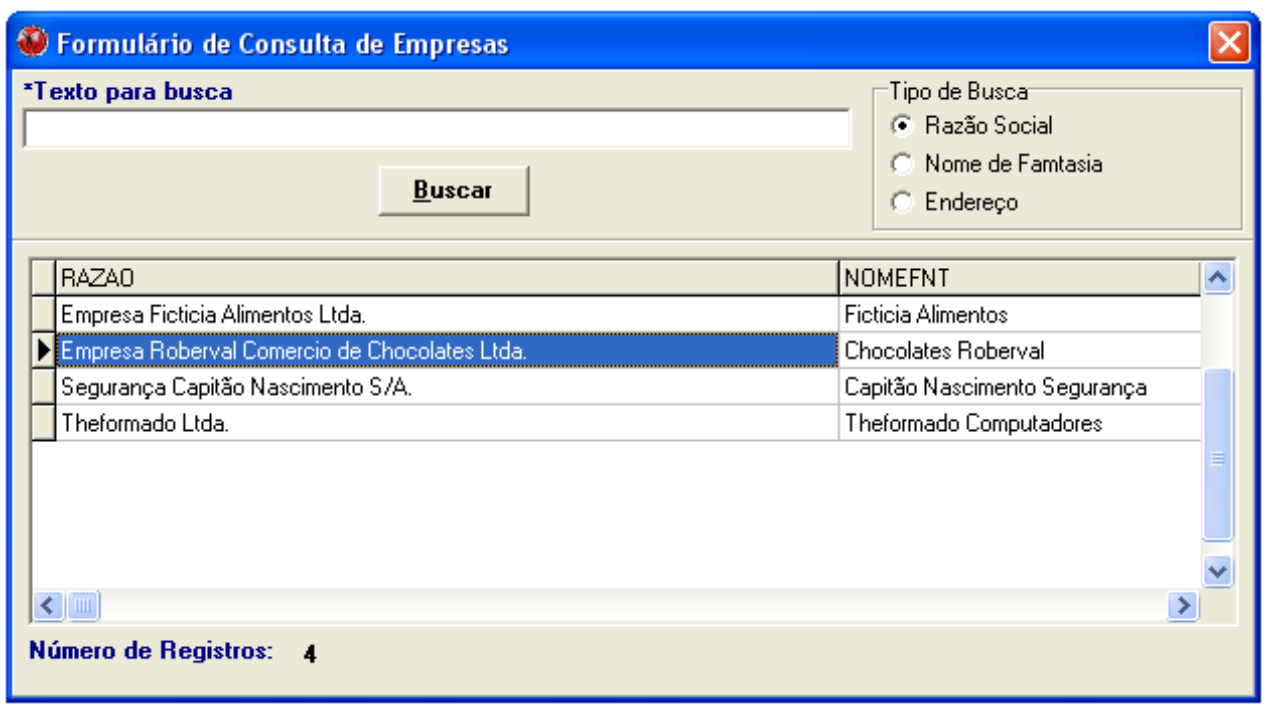

Figura 2 - Consulta ao cadastro de empresas.

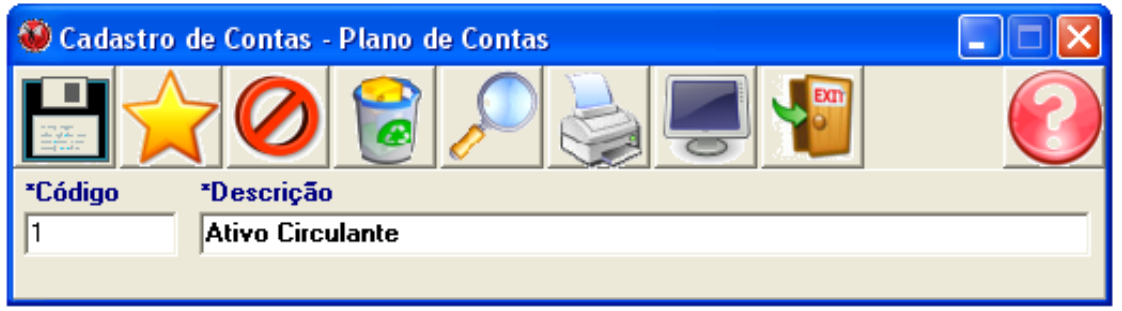

Figura 3 - Cadastro de contas primárias.

A Figura 4 apresenta o cadastro do Plano de Contas da empresa, focando contas mais detalhadas, ou seja, aquelas que estão organizadas dentro dos grupos cadastrados no formulário da figura anterior. Quando o acadêmico iniciar o cadastramento do plano de contas, ele pode utilizar um formulário de busca específico para este aplicativo.

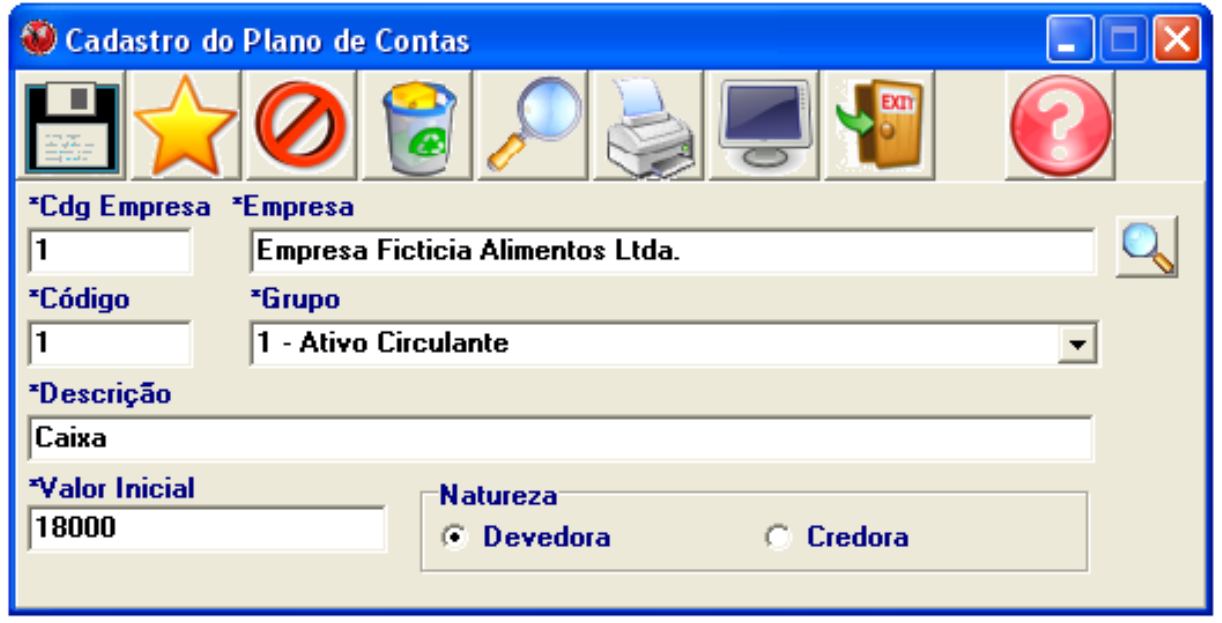

Figura 4 - Cadastro de contas secundárias.

A Figura 5 traz o módulo de cadastro dos lançamentos das movimentações do patrimônio. Este cadastro permite que seja efetuada a primeira forma de lançamento (FAVERO et al., 2005). Durante o processo o usuário pode verificar se o lançamento está sendo realizado de forma correta, apenas observando os dados apresentados em tela, identificando possíveis diferenças nos valores e contas. 
Este formulário permite que o usuário faça o lançamento em diário através da primeira fórmula (simples) de lançamento (FÁVERO et al., 2005; SANTOS et al., 2003). A segunda, terceira e quarta formas não foram implementadas, tendo em vista sua complexidade e ao foco governamental na primeira abordagem. O processo de lançamento consiste, inicialmente, na escolha da empresa foco do registro e, então, o preenchimento dos dados da operação. Para fazer o lançamento em uma conta é necessário que esta tenha sido previamente cadastrada. Assim como no cadastro das empresas, o usuário tem a disposição um formulário para consulta aos lançamentos efetuados.

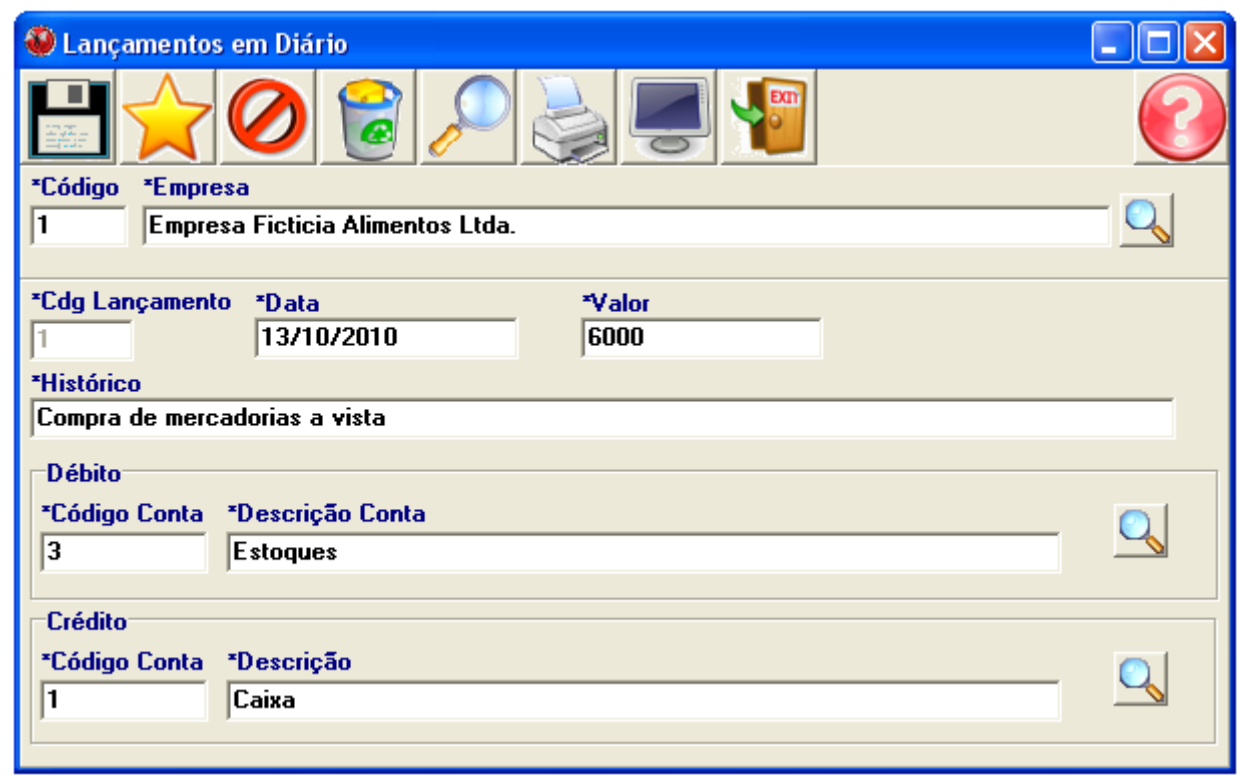

Figura 5 - Cadastro de lançamentos contábeis.

Depois de efetuados os lançamentos de uma empresa, o usuário tem a possibilidade de explorar os demonstrativos e relatórios presentes no Icarus. A Figura 6 contém a tela onde o acadêmico pode gerar o balanço patrimonial, em que é necessário especificar a empresa em questão. Os formulários de elaboração dos demonstrativos funcionam de forma similar, ou seja, basta ao usuário informar a empresa que deseja construir o demonstrativo. O software permite construir o Balancete de Verificação, o DRE, o Livro Diário e o Livro Razão.

A geração de relatórios é feita de duas formas diferentes: através de visualização em tela ou através de impressão. A configuração para impressão segue o formato de folhas A4, padrão para este sistema. Quando o usuário escolher imprimir o arquivo, ele pode fazê-lo mandando diretamente para impressão, ou gerando um arquivo de saída. Caso opte pela abordagem de geração de arquivo, ele pode escolher entre os formatos pdf, xls, rtf e jpg.

Para atender o objetivo de ratificar o aprendizado, o software traz uma série de conceitos referentes ao conteúdo visto em sala pelos alunos. Estes conceitos podem ser acessados a qualquer momento, através do botão Ajuda (em destaque na Figura 6), presente em todas as telas do sistema. Esse botão, além de apresentar os conceitos oriundos da contabilidade, traz também explicações sucintas do funcionamento do método em que o usuário está imerso.

A instalação do Icarus é feita localmente, ou seja, o usuário salva os registros na própria máquina. Porém, ele pode fazer cópias do conjunto de dados salvos e utilizá-los em outra máquina que possua o sistema instalado. Para tanto, inicialmente, era necessário que o usuário tivesse o Firebird instalado em seu computador. Visando evitar 
tal transtorno, construiu-se uma versão do sistema com o banco de dados embarcado, pois desta forma, basta ao usuário copiar as pastas onde estão os arquivos do sistema que este rodará em qualquer maquina com ambiente Windows.

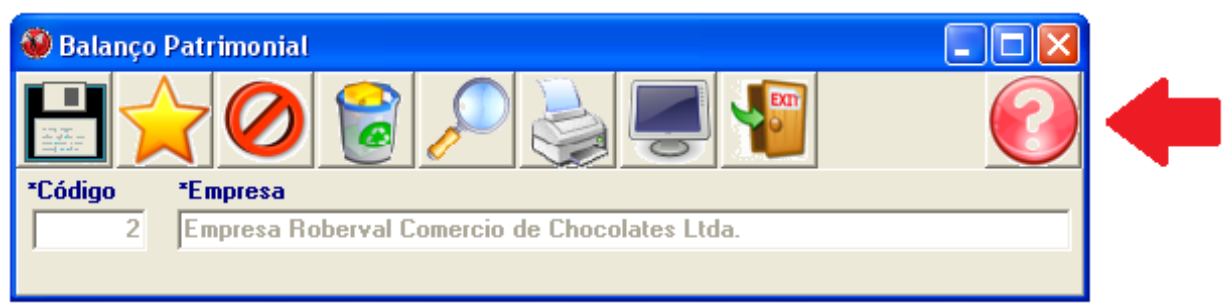

Figura 6 - Geração de balanço patrimonial.

Visando possibilitar a interação do usuário de forma mais eficiente e intuitiva, as telas do Icarus oferecem ícones fáceis de compreender e de operar. O utente pode, através de botões, realizar as operações necessárias. A Figura 7 indica cada operação realizada através de cliques dos botões. A opção 1 aponta para a ação de salvar os dados. O operador pode preencher os campos conforme necessário e salvar tais informações em disco. A opção 2 é utilizada para criar um novo registro a ser editado e salvo. O botão 3 serve para cancelar alterações realizadas e ainda não salvas. O botão 4 serve para excluir o registro aberto, apagando-o inclusive do disco. $\mathrm{O}$ botão 5 é utilizado para fazer consultas aos registros já cadastrados. A sexta opção é utilizada para enviar arquivos para impressão e a sétima serve para visualização em tela. Finalmente, o botão 8 fecha o formulário.

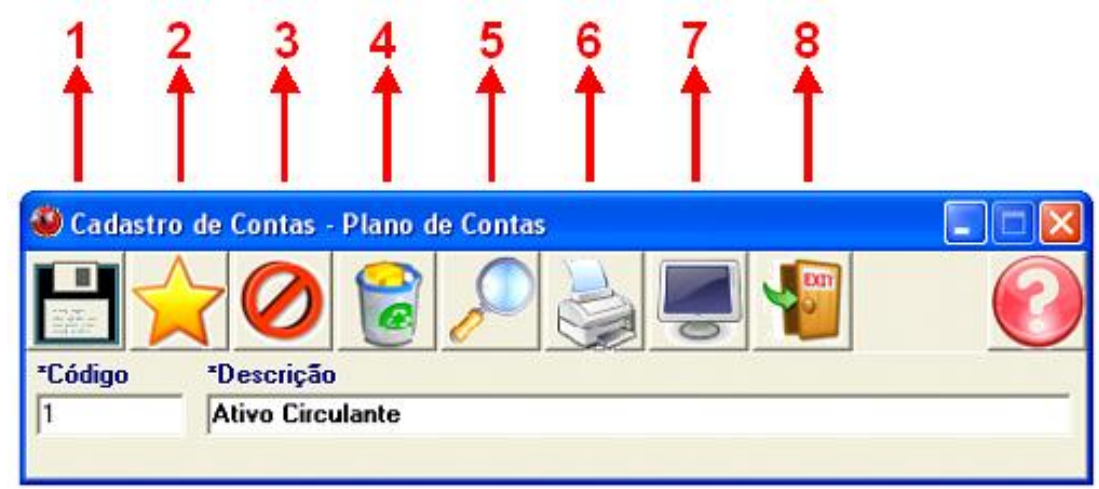

Figura 7 - Funções específicas de operação.

\subsection{Validação}

Com a aplicação do questionário para validação do sistema Icarus, pretendeu-se analisar dois fatores principais: a avaliação da qualidade do sistema e os pontos que este pode melhorar e qual a influência do software no ensino de contabilidade básica.

O questionário foi aplicado a 15 alunos da segunda série do curso de Ciências Contábeis.

\subsubsection{Avaliação da Qualidade}

A primeira indagação feita foi em relação à estrutura do sistema. Os acadêmicos deveriam assinalar a assertiva que achassem mais apropriada para definir a qualidade estrutural do programa, ou seja, as abordagens de menus, formulários, relacionamento entre as telas. Esta questão teve o cunho de descobrir se a forma com que o sistema foi construído era interessante ao usuário no momento de interação.

Neste quesito, 10 alunos afirmaram que a estrutura adotada é boa, enquanto os 5 restantes acreditam que a abordagem estrutural está ótima. Ninguém considerou a 
interface ruim ou péssima. Dentro deste contexto, foi questionada a distribuição dos elementos dentro dos formulários, como botões, campos e textos. Esta abordagem é mais pontual, pois procurou descobrir se as posições dos botões, campos e elementos do formulário estavam em locais interessantes ao operador do sistema. Verificou-se que 7 alunos consideraram tal distribuição ótima, outros 7 a consideraram boa e apenas 1 a considerou regular. Nenhuma resposta apontou para uma distribuição ruim ou péssima.

A interface, elemento importantíssimo de um software, foi avaliada na terceira indagação. Com base nesta resposta, pode-se verificar se a forma visual adotada ficou interessante ao usuário, pois, caso este não se sinta confortável visualmente ao operar um sistema, o aproveitamento da ferramenta pode ser muito prejudicado.

Ao se analisar o resultado, verificou-se que 12 dos respondentes consideraram a interface ótima, enquanto 2 a avaliaram como boa e apenas 1 aluno a considerou razoável. A interface não foi classificada como ruim ou péssima por nenhum entrevistado.

$\mathrm{O}$ quarto item de qualidade foi facilidade de manipulação do sistema. Este inciso é muito importante, pois se um software é muito complexo de ser operado, os usuários tendem a descartá-lo. A preocupação ao longo da construção do Icarus era de que o resultado final fosse prático de se manipular e ao mesmo tempo fácil de compreender o relacionamento entre os formulários. Analisando-se as respostas, verificou-se que houve um equilibrio entre os índices "Muito fácil", "Fácil" e "Razoávell", onde o primeiro foi optado por 5 alunos, o segundo por 6 e o último por 4 acadêmicos. Ninguém considerou o sistema complexo ou muito complexo, o que é um ponto positivo para o sistema.

O software, em todos seus formulários, apresenta opções de ajuda ao usuário. Nestas opções, é possível acessar conceitos sobre o conteúdo trabalhado, bem como algumas dicas de operação do software. Buscando avaliar quão importante é esta abordagem auxiliar, questionou-se quanto à opção de auxilio ajudou ou pode ajudar o usuário. O resultado mostrou que a utilização destes menus de ajuda é importante, pois $60 \%$ opinaram que esta opção ajuda muito na operação do sistema e fixação de conceitos, e os outros $40 \%$ acreditam que ajudam pelo menos um pouco.

Visando avaliar se o processo pelo qual o usuário gera relatórios ficou bom, foi perguntado o que os respondentes acharam da forma adotada. $O$ resultado foi que 4 consideraram o processo ótimo, enquanto o restante dos alunos (11) avaliou como boa a abordagem utilizada. Ninguém considerou tal abordagem regular, ruim ou péssima.

Construídos os demonstrativos, indagou-se acerca da estrutura e formato dos demonstrativos gerados. Assim é possível verificar se é interessante melhorar o formato dos relatórios. Analisando as respostas, verificou-se que $27 \%$ dos respondentes considerou a estrutura e formato dos demonstrativos ótimos, $60 \%$ definiu-os como bons, enquanto os $13 \%$ restantes, consideraram- no regulares.

A preocupação nesta etapa da avaliação foi levantar quesitos, segundo a opinião dos entrevistados, para determinar em quais pontos o sistema construído ainda poderia ser melhorado. As contribuições dos entrevistados foram variadas. Dentre as mais importantes cabe destacar: sugestões de inclusão de atalhos para os botões de interação; cadastrado de históricos de lançamentos; procedimentos de busca automática; correção de textos com pequenos erros de digitação; mudança no controle dos códigos das contas e lançamentos e a alteração na forma da troca de campos.

É importante destacar que todas as contribuições dadas pelos acadêmicos foram construtivas, contribuindo para a correção e evolução do sistema. Efetuadas tais modificações, o Icarus se mostrou mais adequado ao cumprimento de seu objetivo, que é servir de subsídio ao aprendizado de contabilidade.

\subsubsection{Avaliação do sistema como ferramenta educacional}

V. 9 № 2, dezembro, 2011 
Tentou-se identificar aqui como o Icarus pode auxiliar no aprendizado de conceitos básicos de contabilidade. Assim, o primeiro questionamento foi sobre a opinião dos entrevistados acerca da aplicação do Icarus como ferramenta de ensino, no cenário da primeira série do curso de Ciências Contábeis, série para a qual este software foi desenvolvido.

Analisando os dados, se viu que $93 \%$ dos alunos acreditam fortemente que o sistema desenvolvido pode contribuir no aprendizado de contabilidade, e apenas um aluno acredita pouco na utilização do Icarus como ferramenta educacional. Esta avaliação aponta que o software pode colaborar com o ensino dos conceitos contábeis da primeira série.

Considerando que a ferramenta fosse utilizada como elemento auxiliar ao processo de aprendizado, indagou-se quais contribuições poderiam ser aproveitadas. Visando oferecer liberdade de resposta aos participantes, decidiu-se deixar esta questão aberta. As contribuições apontadas pelos alunos foram: oferece um primeiro contato com softwares contábeis; facilita a aprendizagem; possibilita corroborar conceitos vistos em sala, permitindo uma melhor assimilação dos conteúdos; simulação de situações mais reais; aprendizado e contato mais concreto com o plano de contas e lançamentos; geração exata dos relatórios; aquisição de conceitos práticos; facilidade de construção do plano de contas e dos demonstrativos contábeis.

No intuito de analisar o impacto causado pelo Icarus como ferramenta responsável por oferecer o primeiro contato do acadêmico com um software contábil, questionou-se qual o grau de satisfação dos entrevistados perante o sistema. Quatorze acadêmicos consideraram o contato com o sistema como muito satisfatório, enquanto um aluno o considerou satisfatório. Este resultado aponta que a ferramenta construída pode ser muito positiva no processo cognitivo a que se propõe.

Procurando aproveitar o conhecimento dos alunos acerca de outros softwares contábeis existentes, realizou-se uma comparação do Icarus com estes outros sistemas. Questionou-se quanto à apropriação do Icarus como ferramenta educacional em comparação aos softwares que os alunos já conheciam. Verificou-se que 5 alunos consideraram o Icarus bem mais apropriado como ferramenta de ensino contábil, 6 o consideram mais apropriado e os 4 restantes acham que o sistema em estudo é tão apropriado quanto os demais softwares como ferramenta de ensino.

Com o objetivo de quantificar numericamente a avaliação do sistema, solicitouse ao entrevistado que atribuísse uma nota no intervalo de zero a dez ao Icarus, considerando-o como ferramenta de apoio ao aprendizado de contabilidade básica. As notas atribuídas variaram entre sete e dez, perfazendo uma média de 8,8 pontos. Essa avaliação positiva aponta que Icarus é uma ferramenta interessante aos acadêmicos e que pode, com sucesso, ser aplicada como subsídio no ensino de contabilidade introdutória.

\section{Conclusões}

O software desenvolvido mostrou-se muito apropriado à sua aplicação, pois apresenta uma interface com apelo visual que facilita muito sua operação e também possibilita o esclarecimento de dúvidas sobre o conteúdo teórico visto em sala (opção de ajuda).

Tratando-se da necessidade mostrada pelos acadêmicos em utilizar novas metodologias de aprendizado, o Icarus pode oferecer aos alunos um primeiro contato com um sistema contábil, sem gerar o desconforto que ocorre quando este se depara com um software de complexidade elevada. Permite também a ratificação do aprendizado, pois o acadêmico pode abordar o conteúdo visto em sala por uma ótica diferente da teórica. 
Verificou-se, através da validação, que a utilização do Icarus como subsídio ao processo de aprendizado da contabilidade introdutória é bastante promissora. Dessa forma, comprova-se a hipótese da construção de uma ferramenta computacional capaz de auxiliar no processo de aquisição de conhecimento na primeira série de Ciências Contábeis.

Futuramente pretende-se incluir novas funcionalidades, sugeridas pelos acadêmicos respondentes ao questionário e também agregar novas aplicações, estendendo o sistema a ponto de oferecer auxilio ao conteúdo abordado na segunda série do curso, como operações de compra de mercadorias, controle de estoque e gestão da folha de pagamento.

\section{Referências Bibliográficas}

CRISÓSTOMO, V.L., FREIRE, F.S., SILVA, R.N. e MACEDO, C.H.M. Tecnologia da Informação no Ensino da Contabilidade. Revista Brasileira de Informática na Educação, Porto Alegre. v.10, n.1, p.45-52, 2002.

EYERKAUFER, M.L., FIETZ, E.E. e DOMINGUES, M.J. Tecnologia da Informação no ensino da contabilidade: Estudo realizado em duas instituições do estado de Santa Catarina. In: Simpósio de Excelência em Gestão e Tecnologia, 3., 2006, Resende. Anais. Resende: Associação Educacional Dom Bosco, 2006, p1-12.

FAVERO, H.L., LONARDONI, M., SOUZA, C. e TAKAKURA, M. Contabilidade Teoria e Prática. São Paulo: Atlas. $4^{\mathrm{a}}$ ed. 2006. 284 p.

GALVIS-PANQUEVA, A.H. Ingenieria de software Educativo. Santafé de Bogotá: Ediciones Uniandes, 1992.

MORAN, J.M. Os novos espaços de atuação do professor com as tecnologias. In: Encontro Nacional de Didática e Prática de Ensino, 12., 2004, Curitiba. Anais. Curitiba: Pontifícia Universidade Católica, 2004, p.245-253.

NIELSEN, J. Usability Engineering. São Francisco: Morgan Kaufmann. 1994.

PRESSMAN, R.S. Engenharia de Software. São Paulo: McGraw Hill, 6 a ed. 2006. $720 \mathrm{p}$.

SANTOS, J.L., SCHMIDT, P., GOMES, J.M.M., FERNANDES, L.A. Introdução à Contabilidade. São Paulo: Atlas. 2003. 283p. 